\title{
Goldman on Evidence and Reliability
}

Jack C. Lyons

University of Arkansas

I regard reliabilism as one of the major achievements of twentieth century philosophy and Alvin Goldman as one of the chief architects of this important theory. There are others, of course; Alston, Armstrong, Dretske, and Sosa leap to mind, to name just a few, but to my mind, at least, it would be difficult to exaggerate the significance of Goldman's (I979) "What is Justified Belief?” and his subsequent development of the theory in a series of books and papers over the last thirty years. Reliabilism provides an antiCartesian alternative to the internalist epistemologies so widely assumed and deeply entrenched at the time that reliabilism must have initially looked to many like some kind of conceptual mistake (it still does to some). At the same time, reliabilism serves the proCartesian goal of bringing philosophy into consonance with the sciences, thus counteracting the post-Fregean a priorism also entrenched at the time. In at least these two ways, reliabilism has dramatically changed the face of epistemology, and changed it ${ }^{--}$I think $^{--}$for the better.

I find a version of reliabilism to be very plausible; I'm attracted in particular to a version that fits well with much that Goldman has endorsed over the years. My criticism of Goldman's recent work, therefore, will involve matters of detail or elaboration, as I see nothing deeply or fundamentally wrong with Goldman's overarching epistemology. In addition, I'm not even sure that Goldman is really committed to denying anything that I offer here. Much of Goldman's latest epistemological writings have been either polemical (e.g., Goldman 2009b, 20IIb) or aimed at more general theses (e.g., 2009a), and it has been several years since we have gotten a detailed and definitive summary statement of his reliabilism. 
I want to focus on three related issues in Goldman's epistemology. Goldman has recently been making friendly overtures toward evidentialist epistemologies, and although I agree that reliabilism needs some kind of evidentialist element, I disagree with the details of Goldman's proffered rapprochement. More specifically, I think he concedes too much to the evidentialist. In particular, he concedes:

I. that a great many beliefs cannot be justified without evidence, in particular, that some beliefs require nondoxastic evidence

2. that evidential fit can be understood in non-process-reliabilist terms, and

3. that the aforementioned or some similar understanding of evidential fit makes sense of propositional, or ex ante, justification

I will address these in sections $\mathrm{I}^{-3} 3$ below, respectively. I offer some concluding comments in section 4 .

\section{The Need for (Nondoxastic) Evidence}

Goldman has taken an interest in evidence in recent papers (e.g., 2008, 2009a, 2009b, 20IIa, 20IIb), and in some of these (2009a, especially 20IIb) he explicitly advocates a "synthesis" of some stripe or other. In "Toward a Synthesis of Reliabilism and Evidentialism?" (2OIIb) he defends a kind of evidentialist reliabilism, which is intended to improve on both evidentialism and reliabilism by combining elements of both in a single theory. Some notorious problem cases for reliabilism---e.g., BonJour's (I980) case of Norman the clairvoyant and Lehrer's (I990) Truetemp case---can be handled by requiring that the agent have some evidence, or ground, for the belief, in addition to process reliability. That's evidentialism's contribution to reliabilism. ${ }^{\mathrm{I}}$ Not very surprisingly, good evidence will be understood partly or entirely in terms of reliability; that's reliabilism's contribution to evidentialism.

\footnotetext{
${ }^{\mathrm{I}}$ Part of it, anyway. A second contribution is discussed later, in section I.3. In addition, Goldman thinks evidentialism helps reliabilism to make sense of ordinary perception and some kinds of memory beliefs.
} 
Reliabilists who have signed a purity pledge won't like this, but I think Goldman is right to hold that some beliefs require evidential support. We disagree, however, about the nature, location, and extent of the evidential requirement. The view I want to posit, as an alternative to his, is the fairly straightforward view that (a) all evidence is doxastic (i.e., only beliefs can serve as evidence), and (b) some, but not all, beliefs require evidence. Importantly, whether a belief requires (doxastic) evidence is not simply a matter of whether that belief was actually the result of an inferential process; there will be non-inferentially formed beliefs (in Goldman's terms, beliefs resulting from belief-independent processes) that nevertheless require evidential/inferential support in order to be justified. Thus, Goldman's original (I979) theory gets it wrong about belief-independent processes: not all outputs of reliable belief-independent processes are (prima facie) justified. Reliability is sufficient for the prima facie justification of only some belief-independent processes. The upshot of this is that there are some pairs of agents and propositions such that that agent is not justified in believing that proposition unless s/he has (doxastic) evidence for it. Put another way, there are some propositions that cannot be the content of any epistemologically basic belief of some agent. ${ }^{2}$

For example, supposing the agent to be you or me or some other normal human, the following all seem intuitively to be the sorts of belief that can be justified only if the agent has some evidence, in particular, some doxastic evidence:

- the Republicans will take over the Senate in the next election

- dopamine is released in the nucleus accumbens

- evidentialism is false

- Sacagawea was 16 and pregnant when she joined the Lewis and Clark expedition

- the hen in front of me has 42 speckles

All of these seem intuitively to be nonbasic beliefs; the sort of beliefs that require support from other beliefs. (Some of these may be proper objects of memory, in which case doxastic

\footnotetext{
${ }^{2}$ This view is worked out in much more detail in Lyons (2009). A belief-dependent process (Goldman 1979) is
} one that numbers beliefs among its inputs; a process is belief-independent otherwise. 
support may be unnecessary; I'm imagining these here and henceforth to be nerw beliefs, not memory beliefs.) But even Goldman's newer forms of reliabilism don't preclude these from being the outputs of reliable belief-independent processes, which means he gets the intuitively wrong answers, counting these beliefs as justified, even when the agent has no evidence for them. His recent use of nondoxastic evidence doesn't go far enough.

I want to argue two points: (a) that some beliefs do require evidence, in addition to process reliability, but also (b) that no beliefs require nondoxastic evidence. Regarding (b), I should note that Goldman (2OIIb) is more concerned to show that evidentialism needs reliabilism than to show that reliabilism needs evidentialism, so it is hard to know whether he really thinks that some beliefs really do require (nondoxastic) evidence in addition to reliable formation or whether this is a concession to the evidentialist for the sake of argument. If he is not fully committed to this role for nondoxastic evidence (and thus for evidence-utilizing belief-independent processes), then my comments should be read as offering suggestions, rather than objections. ${ }^{3}$

\section{I.I The Nature of Evidence}

I should say what I mean by 'evidence'. The term is notoriously slippery, and an examination of the ordinary language usage is unlikely to be of much help, since the term has a specialized meaning in epistemology, perhaps even a more specialized meaning yet among epistemologists of the ' $S$ knows that $p$ ' crowd.

There are two main questions concerning the nature of evidence, one about the evidence relation, and one about the evidence relatum: what is it to serve as evidence for a belief? and what kinds of things are candidates for serving as evidence? To answer the second question, I defer to what I take to be Conee and Feldman's core conception of the

\footnotetext{
${ }^{3}$ In (2008, p. 77) he seems to be thinking of nondoxastic evidence as a temporary and provisional concession to the internalist, though in (2OIIb) and (20IIa, pp. 46I ff,) he seems to be expressing a stronger commitment to the epistemic role of nondoxastic evidence. Even then, he denies in a number of places (2008, 2009a, 20Ira, $20 \mathrm{Ib}$ ) that all beliefs require evidence to be justified, and even where evidence is relevant to justification, it may contribute to justification without being strictly necessary for justification (20IIa, p. 463).
} 
evidence relatum: one's evidence is limited to those mental states (events, properties, etc.) on which one might base a belief, in particular, beliefs and nondoxastic experiences. ${ }^{4}$ Their mentalism requires that evidence be internal to the mind of the cognizer, and their theory of well-foundedness (i.e., doxastic, or ex post, justification) requires that the belief be based on the evidence. This understanding of evidence is partly terminological---evidence is that on which one does or might base a belief---and partly substantive---the only things on which one might base beliefs in the relevant sense are mental states. ${ }^{5}$ So evidence---the relatum ${ }^{---}$is one's reason, or ground, for a belief, that on which one does or might base the belief, that which one "has to go on in forming beliefs" (Conee and Feldman 2008, p. 88). There is nothing normative about 'evidence' in this sense. Evidence---the relation---on the other hand, is what makes a piece of evidence good evidence, a cogent reason, a justifying ground, etc. Here we can't simply defer to Feldman and Conee, for the debate about what makes something a good reason is too fundamental, too substantive, to simply hand over to the internalists. ${ }^{6}$

\footnotetext{
${ }^{4}$ I call this the core conception because they sometimes invoke other mental phenomena, including unconscious states and even dispositions (Conee and Feldman 20II, p. xxx). From their appeal to dispositions, it would seem that the sorts of mental states involved in propositional justification are not necessarily the same as the ones involved in doxastic justification (since it would seem one does not base a belief on a disposition). Furthermore, they sometimes invoke such mental factors as having learned "something about distinguishing sufficiently apt environments for visual color judgments" (2004, p. I07). It is clear that 'learned' is supposed to be understood nonfactively, but it is not clear whether what is learned is supposed to count as part of the agent's evidence. If so, it seems to cause trouble for Feldman's modest foundationalism; if not, the resulting view seems to conflict with the evidentialist claim that any two agents who have the same evidence are equally justified. One sometimes encounters claims to the effect that "one thing is 'evidence' for another just in case the first tends to enhance the reasonableness or justification of the second" (Kim I988, which is cited apparently approvingly in Kelly 2006). This claim is hard to take seriously, however, for it conflates evidence with justifiers, or J-factors (i.e., anything that is relevant to the justificational status of a belief). I doubt even an evidentialist would hold that evidence exhausts the class of J-factors (the fact that $S$ 's total evidence supports $b$ is a J-factor but not, on the face of it, part of $S$ 's evidence), and in any case, it cannot be the definitional claim it appears to be without begging the question against the very possibility of nonevidentialist views, or views that hold that evidential relations are contingent. Such views might turn out to be false, but they're not blatantly incoherent.

${ }^{5}$ This understanding of evidence might rule out acquaintance (Fumerton 200I) as something on which a belief might be based (if I understand acquaintance correctly). Whether this is a problem for the present understanding of evidence is a question that can be ignored for the present purposes.

${ }^{6}$ Williamson's famous (2000) claim that evidence $=$ knowledge is presumably a claim about the evidence relation; it is a claim about what can (evidentially) justify what, not a claim about what can be based on what. He presumably does not deny that a belief could be based on a falsehood. Similarly, evidential externalism (Silins 2005) is the view that agents identical with respect to their nonfactive mental states might nevertheless fail to have the "same evidence" due to external facts, such as that one but not the other is hallucinating. One might insist on reading this as a claim about how to individuate the evidence relata, but this strikes me as unhelpful and uninteresting metaphysics unless it is also claimed that the relation differs: that, e.g., veridical experiences can justify beliefs that hallucinations cannot.
} 
Conee and Feldman, of course, think that the evidential relation is a matter of a belief's fitting with, or being a proper doxastic response to, a given ground. Goldman rightly complains that they need to tell us much more about this mysterious notion of fit, especially given the absolutely central role it plays in their epistemology. (As far as I can tell, he accepts their view, as I have cast it above, concerning the evidence relata.) He offers instead, a two-factor theory of the evidence relation, which holds that in order for a piece of evidence $e$ to confer justification on a belief $h, e$ must not only (i) be an input to a reliable cognitive process that results in $h$, but there must also (ii) be an objective relation of fit between $e$ and $b: e$ must confirm $h$, render $b$ probable, etc. Modifying his illustrative example slightly, Shirley and Madeleine both believe $b$ to a high degree on the basis of $e$, and the objective confirmation $e$ confers on $b$ is indeed high. However, while Madeleine assigns a high credence to $b$ as the result of her "well honed skills at determining degrees of support," Shirley has no idea how to determine whether $e$ confirms $b$ and is simply guessing. Both Shirley's and Madeleine's beliefs fit the evidence, but Madeleine's belief is justified, while Shirley's is not. One way we might gloss this is by saying that, while $e$ is evidence of $b$ in some detached, disembodied sense, it is only the reliable cognitive process that makes e evidence of $h$ for anyone. In this case, it makes $e$ evidence of $h$, for Madeleine but not for Shirley.

\section{I.2 Doxastic Evidence}

Let us return to the intuitively nonbasic beliefs listed above, like 'evidentialism is false' and 'Sacagawea was I6 and pregnant when she joined the Lewis and Clark expedition'. These beliefs are unjustified for agents more or less like us, unless the agent has some argument or other beliefs to support these beliefs. Yet we can imagine the target beliefs resulting from reliable processes, even processes that take nondoxastic experiences as inputs, and it doesn't change our intuitive verdict. 
Although Goldman's view has always been a kind of process, rather than indicator, reliabilism, he has been making explicit efforts recently (2009b, 20IIa) to emphasize the superiority of process reliabilism over indicator reliabilism and related views. Here is another point where I agree wholeheartedly with Goldman; process reliabilism is vastly superior to indicator reliabilism---an issue to which we will return in section 2. For now, let us simply notice that it is all too easy to use these intuitively nonbasic beliefs against indicator reliabilism: I have some arbitrary sensation that causes me to believe that Sacagawea was I6 and pregnant when she joined the Lewis and Clark expedition; because this belief is true, the sensation is a reliable indicator, and the theory counts the belief as justified. It is less easy to cause trouble for process reliabilism, however; the examples will have to be elaborated in much more detail.

Consider, then, the reasoning you and I would go through to figure out that Sacagawea was pregnant when she joined the expedition. Imagine we start out knowing that she had a six month old infant in August of 1805 , and that she joined the expedition in November of I804. Counting backward from August '05, we reason that the baby must have been born in February I805, and so Sacagawea must have been pregnant for several months before that (approximately nine; a severely premature infant wouldn't have lived long in the wilderness, in 1805 ), which makes her about six months pregnant as of November I804. This is a perfectly typical, justification-conferring sort of inference.

Now suppose that Sarah (an otherwise normal human) reasons similarly, from the same premises (Sacagawea joined in November'o4, and she had a six-month-old in August '05). She uses the same reliable reasoning process you and I do, but with an important difference: Sarah's reasoning is entirely unconscious; she is neither aware of the lemmas nor of the truth of the various suppressed premises. Sarah doesn't know (i.e., has no belief about) what month or year the baby was born, how long a typical pregnancy lasts, how many months are in a year and what order they come it, etc. To make matters worse, suppose that Sarah acquired this reasoning capacity as the result of a neurosurgery carried out on her last 
night without her knowledge; yesterday afternoon she'd have concluded nothing from these same premises. Intuitively, Sarah is not justified in this belief, even though it results from a reliable process.

We could imagine a variant case where even more of the process is unconscious: the visual experience you and I have when seeing the printed sentences 'Sacagawea had a six month old infant in August of I805' and 'Sacagawea joined the Lewis and Clark expedition in November of I804' serves as input to the pertinent processes, even though Sarah herself doesn't even (consciously) know how to read.

There may be cognizers who could solve this problem intuitively, in a single step, without doing any math, simply "seeing" that Sacagawea must have been pregnant, in the way that I might "see" that two glimpses of a clock are (some multiple of) six hours apart. But I am not such a cognizer, and I presume Sarah's surgery need not make her one either. Once again, then, we have a case where reliability is not sufficient; the agent must have some evidence. Not only evidence; the agent must have some doxastic evidence, and in fact, the agent must have some fairly specific doxastic evidence. It's not just that she's basing the belief on a reliable indicator; she's using the same process we are (hence, an equally reliable process) but without having the same evidence.

Goldman does, of course, allow that evidence may be required for the justification of some beliefs. However, this requirement is not strong enough, for he needs to require not just evidence, but doxastic evidence. Nondoxastic evidence is not enough to help with the relevant cases. For those cases where reliabilism needs to add an evidence requirement, it is a doxastic evidence requirement that is needed. I agree with Goldman that not all beliefs require evidence; but I insist that those that do, require doxastic evidence, and experiential evidence contributes nothing to reliabilism.

The most obvious cases of unjustified though reliably formed belief involve the sudden, perhaps unknown to the agent, advent of novel cognitive capacities. Truetemp is like this, and the Norman case is most compelling if the details are filled in this way (see 
Lyons 2009 for a lengthier discussion). Suppose, then, that Norman and Truetemp have nondoxastic sensations that feed into reliable clairvoyance and temperature detecting processes, respectively. We can imagine that the sensations are old and familiar (normal thermal sensations, spontaneous visual imagery) but that the reliable process, with the accompanying belief, is novel. Yesterday, when Truetemp had this temperature sensation, he wasn't justified in believing that it was IO $3^{\circ}$ outside, but today he is? This doesn't seem very plausible, but it gets even worse if we vary the sensations. Truetemp's surgeons may have arranged it so that he has an unusual auditory sensation, whose pitch correlates with ambient temperature, an auditory sensation that feeds into a reliable temperature-sensing process. Truetemp, of course, has no reason to believe he has this new capacity, that the auditory sensations reliably covary with temperature, etc. Intuitively, this experiential evidence variation on the Truetemp case provides us with an instance of unjustified belief. In fact, this belief seems just as intuitively unjustified as the original Truetemp case. (Analogous considerations apply to the Norman case, but I won't bother making the modifications explicit.) Again, it is not just that Norman and Truetemp are basing unjustified beliefs on reliable indicators, but they're using processes that are reliable in whatever sense our perceptual processes are reliable.

Presumably, however, if Truetemp were justified in believing that these sensations correlated in the appropriate way with the ambient temperature, then his beliefs about the latter would, in fact, be justified. So nondoxastic evidence doesn't justify Truetemp's belief, while doxastic evidence would. If, therefore, we want to handle the Truetemp case by requiring him to have evidence for this temperature belief, it should be doxastic evidence that we require.

Goldman's aforementioned two-factor theory might seem to offer him some help in responding to these sorts of objections. Goldman might argue that the experiences I'm invoking in my counterexamples do not fit with the beliefs they cause; thus, even though the 
process reliability factor is satisfied, the fittingness factor is not, so his theory doesn't get the wrong result after all.

This response won't help Goldman, however. First, let us consider the view that evidential fit is a necessary, two-place relation: if $e$ is evidence of $b$ for $S$, then $e$ necessarily, and for any $S$, fits with $h$. I call this view "evidence essentialism." For evidence essentialism to ward off the present counterexamples, one would have to claim that no possible agent could have precise temperature beliefs that are justified by the auditory or thermoceptive sensations described above. But surely some possible agent could have justified, epistemologically basic, and highly precise beliefs about the ambient temperature, and if experiences ever serve as evidence for basic beliefs, these experiences seem like fine candidates for doing so. Similarly for clairvoyance: clairvoyance could produce justified basic beliefs in some possible organisms, and the same sensation that intuitively does not justify Norman in believing that $p$ could justify some other possible creature in believing that $p$. If so, then that sensation fits with $p$, in the relevant sense. ${ }^{7}$

In any case, and to his credit, Goldman rejects this view of evidential fit in favor of one that sees it as a contingent four- (or more-) place relation among the evidence, the justificandum belief, the organism, and the environment. Goldman (20Irb) instead endorses a reliable indicator theory of evidential fit (factor (ii)), to complement the process reliabilist factor (factor (i)) that is also necessary for evidential justification. However, this understanding of evidential fittingness doesn't help with the present problem either. Truetemp's sensations do reliably indicate the truth of the corresponding beliefs; similarly for Norman (and Sarah).

So the Norman and Truetemp cases stand; they show---or seem to, anyhow---that certain beliefs require doxastic evidence, that reliability is not enough. Goldman's new

\footnotetext{
${ }^{7}$ It is easy to come up with further counterexamples. Electeroception, magnetolocation, ultraviolet and infrared (heat) vision, echolocation, and the heightened chemosenses of other animals offer a small sampling of actually realized senses which, in some possible organisms, yield justified basic beliefs. If these beliefs require (nondoxastic) evidence, and if evidence essentialism is true, then these very same sensations would, were they to occur in us, fit with certain of our beliefs. They wouldn't justify these beliefs for us, however, so if these beliefs are evidentially justified, evidence essentialism is false. A similar argument is pursued in Lyons (forthcoming b).
} 
conjunction of indicator reliability and process reliability does not make headway with these cases.

One could, of course, take a very hard line on reliabilism, biting the bullet and insisting that reliability really is sufficient for justification and thus that Norman and Sarah and the others are justified, our contrary intuitions notwithstanding. This has never been Goldman's approach, however; he has always taken these sorts of objections seriously. That he has always done so is an important feature of his view; among other things, it makes it much harder for the internalist to get away with the apparently popular claim that the externalist is simply changing the subject and talking about something other than what the internalist has always been talking about.

\section{I.3 The Role of Experience}

It is not just that nondoxastic experiences might account for what is missing in certain well-known cases of reliably produced but unjustified belief. Goldman has another argument for thinking that reliabilism would be improved by incorporating experiential evidence. The argument is that experiences that have not been fed into any instantiated processes can nevertheless serve as defeaters for certain beliefs; the best explanation for this is that the experiences serve as undermining evidence to these beliefs. For example, Sidney has a prima facie justified belief that it will be sunny today, but this belief is defeated by his current perceptual experience, despite the fact that this experience is not producing any contrary beliefs (20Irb, p. xxx).

This is an odd argument for Goldman to espouse, for two reasons. First, as he is well aware, there is a competing explanation that explains the defeat without any mention of evidence. Second, on Goldman's two-factor theory of evidence, this experience doesn't count as evidence anyway.

Goldman has offered different accounts of defeat over the years, but perhaps the best is his original (1979) alternative reliable process account (ARP), according to which, S's 
prima facie justification for $p$ is defeated just in case there is an alternative reliable process available to $S$, which, if used in addition to or instead of the one actually used, would have resulted in $S$ 's not believing that $p$. This view is problematic in various ways, some of the details of which will concern us later, but if it is even remotely on track, it offers a simple solution to the current problem. If Sidney is having a perceptual experience as of walking in a rainstorm, then---assuming Sidney is a reliable perceiver---there is a reliable perceptual process available to him which would result in his not believing that it's sunny, which, by ARP, defeats his justification for believing that it's sunny.

Notice that the ARP solution only gives us the desired result (that Sidney is unjustified) if Sidney's perceptual processes are both reliable and available to him. But this seems just right; if we waive either of these assumptions (e.g., suppose Sidney is terribly unreliable in these circumstances or that he is suffering from an agnosia that makes it impossible for him to form perceptual beliefs), then Sidney no longer seems to be unjustified in believing that it is sunny. Such considerations, in fact, make it look as if ARP actually handles the case better than an evidentialist theory. Supposing the experience to be defeating evidence when Sidney's perceptual processes are reliable and available, either (a) the experience remains evidence when these processes are not reliable and available, or (b) the experience ceases to be evidence in these conditions. If (b), then something very much like ARP is already being tacitly smuggled in, and the evidentialist view is not a genuine alternative; if (a), then Sidney ought to be unjustified in believing it's sunny even if he has the agnosia, but he does not seem to be unjustified in this case.

Goldman has not, of course, forgotten about ARP. But he thinks it is problematic in various ways and that the evidential view improves on it (20Irb, note 15 ). I am in the process of arguing that the evidential view does not improve on it, but I want to also insist that we will need to hang onto something like ARP anyhow, for there are cases of defeat that don't appear to involve evidence. Recall Kornblith's (1983) case of the headstrong physicist whose pride prevents him from even hearing a colleague's crushing objection to his view; 
intuitively, the physicist is unjustified. Goldman (I992) discusses this alongside Holly Smith's example of a doctor who has good prima facie reasons for believing that $p$ but has medical journals on her desk that she should have been reading and that would have undermined these prima facie reasons; the doctor is unjustified. These are highly problematic cases for standard versions of evidentialism, but they are easily handled by ARP or something like it. Feldman and Conee (I985) respond to Kornblith's physicist case by claiming that, so long as the physicist genuinely doesn't hear the objection---even though he could, were he to stop being so dogmatic for a moment---his original belief remains justified and undefeated. Goldman could take this route, but it doesn't strike me as an attractive solution, and I doubt it would strike other reliabilists as attractive either. Thus, we seem to need some kind of ARP clause anyhow; why not let it do double duty and handle the Sidney case as well?

The second complaint is that, on Goldman's two-factor theory of evidence, the Sidney case isn't a case of evidential defeat anyhow. Let us suppose that the experience does fit the belief that it is not sunny outside, so the fittingness factor is satisfied. Still, as Goldman insists, Sidney's perceptual experience of rain does not feed into any instantiated process, so the process factor is not satisfied. Goldman can't claim that this is a case of defeat by contrary evidence, for this is not, on Goldman's view, a case of evidence! He could, of course, expand the reliable process factor to include uninstantiated but available processes, but this defeats the purpose of the example, which was supposed to render ARP and its ilk unnecessary. The expanded view would be a version of ARP with extra (evidential)complications tacked on and no good indication that those complications were really paying their own way.

Alternatively, Goldman could claim that fittingness yields propositional justification, while using a reliable process is necessary for doxastic justification. (The distinction between propositional and doxastic justification will get more attention later; roughly, propositional justification attaches to a proposition if it's in some sense the epistemically 
right thing for the agent to believe, whether the agent does or doesn't believe it; doxastic justification attaches only to beliefs that are properly held.) So Sidney is in a state that indicates it's raining, which thus propositionally justifies Sidney in believing it's raining, and this propositional justification defeats his justification for believing that it's sunny. Goldman hints that he might intend for fittingness to capture propositional justification; considering a different case where the subject's experience serves as a reliable indicator, he asks "[m]ust we add a process-reliability component ... ? Yes. Otherwise ... we won't have a satisfactory account of doxastic as opposed to propositional justifiedness" $20 \mathrm{IIb}, \mathrm{xx} 26$ (however, also see 20Irb, note II). This would evade the worries just leveled, but only if it is plausible to hold that reliable indication yields propositional justification, a topic I return to in section 2 below. To anticipate, I think it is not. Thus, the Sidney example does not argue for any evidential role for nondoxastic experiences.

\section{I.4 Perception and Nondoxastic Evidence}

I have been arguing against Goldman's attempt to strengthen reliabilism by the incorporation of nondoxastic evidence, claiming that this constitutes too much of a concession to evidentialism. Yet I have insisted myself that a pure version of reliabilism is off the table, that some beliefs require evidence in addition to process reliability. In fact, Goldman never explicitly even claims that evidence is necessary for the justification of any beliefs, only that it can contribute to justification. Why should my appeal to doxastic evidence be any less of a concession to evidentialism than Goldman's appeal to nondoxastic evidence?

First, though Goldman doesn't explicitly require doxastic evidence, I think it is an inescapable addition to any adequate reliabilist epistemology. The Sacagawea case above, as well as the Truetemp and Norman cases, seem to indicate that doxastic evidence is sometimes required for justification. These agents are unjustified, and supplying them with 
the right experiences doesn't help---what they are missing are beliefs. ${ }^{8}$ More modestly, I think that anyone who does not just deny these intuitive verdicts in favor of a simple or pure reliabilism will have to incorporate doxastic evidence, and Goldman does not want to deny these intuitive verdicts. Provided that the theories agree about which beliefs require doxastic evidence, a reliabilism that countenances only doxastic evidence involves less of a concession to evidentialism than one that countenances that, plus a host of nondoxastic evidence.

This leads to a more significant point. It is very plausible to hold that perception is epistemically belief-independent, in the sense that perceptual beliefs can be justified without any evidential support from other beliefs. If we conjoin this claim with the view that all evidence is doxastic evidence, then we end up with an epistemology according to which perceptual beliefs are justified in a way that does not involve evidence of any sort. Clearly this view is highly inimical to evidentialism. Goldman does insist on the possibility of justified beliefs that don't involve evidence: introspective beliefs, preservative memory beliefs where the original evidence has been forgotten, etc. ${ }^{9}$ But his treatment of clairvoyance makes it out to be a quasi-perceptual capacity, and this leads him to the claim that nondoxastic experiences have an evidential role to play in perception and in those cases of memory that involve distinctive memorial experiences (20IIb, Xx. 22-3).

Notice I am only denying that experiences play an evidential role, not that they play an epistemic role of some other sort. My perceptual experience might produce in me a justified introspective belief that I'm appeared to F-ly, and if I'm justified in thinking that being appeared to F-ly typically accompanies something's being F, then I have an additional justification for thinking something is F. Experiences might therefore play an indirect role in producing propositional or ex ante justification for perceptual or memory beliefs (or

\footnotetext{
${ }^{8} \mathrm{I}$ am not endorsing a general metabelief or doxastic ascent requirement, of course. The existence of some beliefs for which other beliefs were needed never was a good argument for coherentism.

${ }^{9}$ In Goldman (2009a) he discusses an abandoned project to develop an internalist-externalist hybrid by insisting that the correct J-rules had internal antecedents (e.g., if you're appeared to F-ly, then it is permissible to believe that something $\mathrm{F}$ is nearby). Presumably, he abandoned the project in part because of nonevidentially justified beliefs of the sort just mentioned.
} 
rather, inferential beliefs with the same content as perceptual or memory beliefs), without ever playing a direct or evidential role or figuring in the doxastic justifiedness of ordinary unreflective perception and memory. The role for experiences is quite indirect on this view, however. Experiences are mere causes, rather than reasons, in just the way external objects are. As such, their role is parasitic on the reliability of introspection, the justification for the belief that there's usually something F nearby when I'm appeared to F-ly, and so on. In any case, I am not committed to denying that having experiences is epistemically better than not having them.

A basic belief is standardly conceived as one that does not depend on evidential support from other beliefs for its justification, though this is compatible with its requiring evidential support from nondoxastic states. If, as I have been urging, all evidence is doxastic evidence, then the detente with evidentialism is possible only where nonbasic beliefs are concerned. Evidence plays no role in the justification of basic beliefs. Provided that we have some antecedent or independent way of distinguishing basic beliefs from nonbasic beliefs--something we will all need if, as I say, some beliefs do require doxastic evidence and some do not---then this gives us our distinction between the beliefs that require evidence and those that do not. Goldman, however, will require not just a way of distinguishing basic from nonbasic beliefs, but also a way of distinguishing between those basic beliefs that require evidence and those that do not.

\section{Reliability and Evidential Fit}

There is an intuitively appealing idea, according to which if one thing is evidence for another, then that evidential relation is an objective feature of the world, one which does not depend in any way on $u s$, or any other cognizers. This would prop up a second intuitively appealing idea: that evidential relations are already out there when organisms come along and make use of them; justification results from cognizers exploiting preexisting evidential 
relations in the world. Despite their intuitive plausibility, however, these are highly problematic claims, especially in the context of process reliabilism.

"Evidence essentialism" is the already encountered view that if $e$ is evidence of $b$ for $S$, then necessarily, and for any $S, e$ is evidence of $h$. We saw some problems for evidence essentialism above (see also Lyons 2009, forthcoming b), and Goldman isn't tempted by such a view, so I won't discuss it further. The first of our two appealing ideas either is evidence essentialism or is near enough as to be subject to very similar problems.

The second appealing idea is considerably more modest, for it recognizes that an evidence relation might be perfectly objective without being cognizer-independent. If, for example, a certain sensation in me reliably indicates a certain chemical property, then this is a perfectly objective fact---it is not, for instance, dependent on my beliefs about the matter--even if in other organisms the same sensation occurs randomly, or if it indicates something different for them. Even though indication is thus cognizer-dependent, it is still objective and "out there in the world," to be exploited, at least in the very important sense that it is not subjective, or dependent on that cognizer's perspective or beliefs.

This second idea is, I think, what Goldman intends to capture with the fittingness factor of his two-factor theory of evidence. The problem with it is one which I expect Goldman may appreciate: reliable indication is not really an epistemic good-making feature and hence not properly included as a factor in a theory of evidence.

\section{I The Epistemic Irrelevance of Indication}

Recall the standard examples. Shirley is terrible at determining confirmation levels but guesses that the probability of $b l e$ is high, thus believing $b$ on the basis of $e$ (in a case where the probability of ble really is high). Sarah believes that Sacagawea was pregnant on the basis of reliable evidence whose evidential significance Sarah is not in a position to appreciate. The novice bird watcher believes that there's a pink spotted fly catcher on the basis of a visual experience identical to that which justifies the expert in believing thus, even 
though the novice is leaping to conclusions (Feldman 2003). To say that the evidential relation consists of two factors, one of which is satisfied in these cases, is to suggest that there is something these agents are doing right, even if they fall short of justification. But this seems wrong; why think these agents are doing anything epistemically right at all? Goldman hints that they are propositionally but not doxastically justified (20Irb, xx 26), but if so, this only shows the scant value of propositional justification (section 3, below). Even though, e.g., Shirley's belief "fits" her evidence, it seems that there is absolutely nothing that she's doing epistemically right, no more so than believing truths for bad reasons. Given the unreliability of the process she uses---and the unreliability of all the processes she could feasibly use---she is no better off epistemically in believing a proposition that fits her evidence than one that does not.

To take another of Goldman's own examples (forthcoming): Chad believes that $p$ on the basis of $p \vee q$ and $\sim q$, but not because he appreciates the validity of disjunctive syllogism or has that rule "hard wired" or the like, but rather, because any time he encounters a proposition of the form ' $p \% q$ ' (where ' $\%$ ' is some logical operator) he infers $p$. Again, it seems that Chad is completely unjustified in believing $p$. He is no better off epistemically than he would have been had he believed $p$ on the basis of $p \vee q$ and $q$, or some other nonreliably-indicative ground.

A well-known fact that causes problems for many epistemological views is the fact that the conditional probability of any necessary truth given any piece of evidence is I. On Goldman's view, it appears that even the most obscure necessary truth has something going for it, for whatever reason may believe it. Worse, believing a necessary truth for some apparently frivolous reason will result in a better epistemic status than believing it for no reason at all. Let $w$ be whatever the true proposition is that states the $234^{\text {th }}$ digit of the decimal expansion of pi. I have no idea what the 234th digit is, but if I believe $w$ on the basis of the claim that cats have fur, then I'm epistemically better off, on Goldman's view, than if 
I merely believed $w$ without basing it on anything. This is because $w$ fits my evidence in the one case (where I have evidence on which I'm basing it) and not in the other case (where I don't). But surely this is wrong; not only have I pulled $w$ itself out of the air, but I've pulled 'cats have fur' out of the air as well, as a belief on which to base $w$. If anything, this ought to make my epistemic position worse, not better. ${ }^{10}$

Thus, reliable indication adds nothing to the agent's evidential status, and Goldman's two-factor theory of evidence should be rejected in favor of one that posits only a single, process reliability, factor. Goldman claims that "on one dimension of justifiedness---the fittingness dimension---Shirley and Madeleine's doxastic attitudes vis-a-vis $b$ deserve the same rating. . . A two-factor theory handles this case nicely. But no single-factor theory, of either the purely evidentialist or purely [process] reliabilist sort, can do so" (20IIb, xx I2-13). But if the dimension on which they deserve the same rating is not genuinely an epistemic dimension, a "dimension of justifiedness," then a single-factor theory (of the purely process reliabilist sort) does just fine. ${ }^{\text {II }}$

Traditional versions of foundationalism used to claim that beliefs about the current contents of one's own mind were basically justified because they were infallible. But this claim was always problematic, for we have plenty other beliefs that are infallible but not in the slightest bit justified, e.g., lucky guesses about obscure necessary truths. Infallibility is just an extreme form of reliability, and the epistemic importance of reliability was, of course, one of the central insights of Goldman's original (1979) defense of justificational

\footnotetext{
${ }^{10}$ One might deny that this is the right understanding of reliable indication, because in this case the evidence doesn't raise the probability of the target belief, the latter already being I. Such a response, however, would either preclude using the notion of fit to account for the evidential status of belief in necessary truths, or require some other understanding of fit.

${ }^{\mathrm{II}}$ I assume that the evidence relation of concern to us here is an epistemically significant one. Reliable indication might suffice for evidence in some very detached and disembodied sense, but it is insufficient for evidence in some epistemologically significant sense. If the connection between evidence and propositional justification is at all close, then we need an understanding of evidence (or having evidence) that is far less detached. Even Conee and Feldman (2008) deny that $e$ 's entailing $b$ makes $e$ evidence of $b$ for $S$, provided that $S$ is in no position to understand or be aware of the entailment, presumably because it destroys the connection between evidence and propositional justification. $S$ might know $e$ without being at all propositionally justified in believing $h$. This detached understanding of evidence is popular in the philosophy of science literature but not in epistemology (even, I think, among evidence essentialists). I don't mean to deny the existence of evidence in this detached sense, although I am not at all sure the notion is coherent, and it is not part of my present concern. Thanks to Tom Senor for clarification on these issues.
} 
reliabilism. But the other, equally important insight---without which the epistemic significance of reliability is at best unclear---was the importance of processes. No matter how objectively likely $p$ is to be true, no matter how conditionally probable $p$ is relative to a body of evidence, belief in $p$ is unjustified if it is arrived at by way of the wrong kind of process. We think now of "What is Justified Belief?" as arguing primarily for an externalist theory of justification, but it is clear that one of Goldman's primary concerns at the time was to establish a genetic or historical theory of justification, one that saw justification as essentially involving ways of coming to believe. These are not independent concerns. The epistemic importance of reliability is, I submit, yoked to and dependent on the epistemic importance of belief-forming processes. Over and over, Goldman (1979) gives us examples of intuitively unjustified beliefs that nevertheless satisfy all the requirements endorsed by previous epistemologists who were not sensitive to the role of processes. Furthermore, the intuitive verdict, then and now, seems to be not just that these beliefs are partly flawed but that they have nothing going for them, justificationally speaking, save perhaps for some very raw potential, were the agent to form beliefs in a vastly different manner. ${ }^{\mathrm{I2}}$

\subsection{Indicators and Processes}

Goldman has never lost sight of the epistemic significance of ways of coming to believe, and he is well aware of the differences between process reliabilism and indicator reliabilism. Reliable indication does not imply process reliability, and this gap allows for the objections to indicator reliabilism Goldman and I have been pressing, here and elsewhere (Goldman 2009b, 20IIa, 20IIb; Lyons 2009, 20II). But does process reliability require reliable indication? More specifically, suppose that a reliable process takes $e$ as evidential

\footnotetext{
${ }^{12}$ Perhaps, despite Goldman's suggestive linking of propositional justification and evidential fittingness, satisfaction of the fit factor does not imply that anything is being done right; maybe both factors must be satisfied before any positive epistemic status accrues. This would block the inference from ' $\mathrm{S}$ satisfies the fit factor' to 'S is doing something epistemically right'. But this doesn't work, unless the fit factor plays a very different role than the process reliability factor, for it is clear that one can have a positive epistemic status by satisfying the reliability factor, even if the belief doesn't fit any evidence. If we can have justified beliefs that aren't based on any evidence---as Goldman agrees we can---then we can achieve justification by satisfying the reliability factor but not the fit factor.
} 
input and produces $b$ as output, does this require that $e$ is a reliable indicator of $h$ ? To answer this, we'll need to get a bit more clear on the crucial concepts of both indication and processes.

Reliable indication is supposed to be a relation that holds both from a belief to a belief and also from a nondoxastic experience to a belief. These are significantly different, however. Let's say that state indication is when the occurrence of state $e$ indicates the truth of $b$ (i.e., the conditional probability of $b$ given the occurrence of $e$ is high), and that content indication is when the truth of $e$ indicates the truth of $b$ (i.e., the conditional probability of $b$ given the truth of $e$ is high). The natural move for indicator reliabilists is to invoke content indication for doxastic evidence and state indication for nondoxastic evidence. ${ }^{\mathrm{I} 3}$

Now, depending on how one individuates processes, the connection between indication and process reliability might be tight indeed. Comesaña's (2OIO) evidentialist reliabilism insists that, if $e$ is the evidential input to a process that results in the belief that $b$, the relevant process type is the type producing a belief that $b$ on the basis of $e$. But the reliability of that process type is simply going to be the conditional probability of $b$ given $e$. That is, Comesaña's proposal is a type of indicator reliabilism, with some surface features of process reliabilism. To keep the process/indicator distinction from collapsing, the individuation of the processes has to be divorced from the contents of the representations over which the processes operate. If inferring $p$ from $q$ counts as a process, then process reliabilism will face the very problems that plague indicator reliabilism, as does Comesaña's theory, for example. The idea behind process reliabilism is that for me to be justified in inferring $r$ from $s$, this must be due to a more general competence, a competence for inferring truths (like $r$ ) from things like $s$. Perhaps it is part of the very nature of a competence to be at least somewhat general: mere consistency of inference (I always infer $r$ from $s$ ) is compatible with a

\footnotetext{
${ }^{13}$ Alston (I988) seems to be opting for state indication across the board, on the rationale that doxastic grounds can confer justification only if themselves justified, which means that they will be likely to be true, so whatever a (justified) belief content-indicates, it will probably state-indicate as well. This move amounts to foregoing an indicator reliabilist analogue of conditional reliability (Goldman 1979), and the view suffers accordingly. Goldman (2OIIb) opts for content indication across the board, which commits him to claiming that the justifying experiences have contents and even truth values. What I just called the "natural move" still seems natural to me, even if it isn't especially popular.
} 
justification-killing form of luck; I'm not necessarily competent just because I get this one thing right, even if I get it right habitually. ${ }^{14}$

With processes and indication slightly better understood, we can return to the question whether evidence-involving process reliability requires reliable indication. One way in which a process might be reliable without its evidential inputs reliably indicating its outputs is if the process requires other inputs that don't count as part of the agent's evidence. Such inputs may include unconscious detection of lighting conditions, direction of gravitational pull, even pheromones, which do not count as part of the agent's evidence, in part because of their inaccessibility to the agent, and in part because their role as evidence is far from apparent. Depth perception utilizes unconscious cues, like binocular disparity, and conscious cues, like "aerial perspective," whose status as cues and whose evidential significance is known to few aside from perceptual psychologists and painters. I do not assume in general that all evidence must be consciously dwelt upon, but I do think that for something to count as my evidence for a belief I must be at least tacitly aware of its evidential significance, which requires it to be at least potentially conscious. If I can remain justified in believing $p$ while justifiedly believing $-q$, then $q$ is not an indispensable part of my evidence for $p$. Such is the case with these arcane or unconscious perceptual cues. So even if the total input to the process reliably indicates a given belief, the evidential part of that input might not: the probability of $b l e+n$ might be high even though the probability of $b l e$ is low. This is presumably the function of the nonevidential inputs, to make the overall process more reliable.

\footnotetext{
${ }^{\text {I4 }}$ It would be good to have a detailed theory about the individuation of processes. Though I can neither develop nor defend it here, I think that the best way to go is perhaps largely to hand the problem off to empirical psychology (at least so far as normative epistemology [Goldman I992] is concerned). Psychology is concerned to state lawful generalizations with as much detail and hence predictive power as possible. If we individuate processes as the narrowest process type describable by the laws of psychology, we will avoid Feldman's (1985) "no distinction" problem; any variable recognized as relevant by psychology (lighting conditions, attention level, degree of match between geon description and stored object model, etc.) can figure into process individuation. At the same time, because we are constrained by the lawes of psychology, Feldman's (I985) "single case" problem is likewise avoided, for psychological laws don't cut things finely enough to rule out all but one case. I think, though this would have to be worked out, that this proposal would also rule out a Comesaña-style appeal to contents, thus preventing the process/indicator collapse we saw above.
} 
Even the total input to a process need not reliably indicate the output in order for the process to be reliable. Process reliability is determined by what the process does across the range of its inputs; it is something like the conditional probability of true output given some typical input or other, not the conditional probability of true output given this particular input. Unless this particular input is the only input the process ever receives, these values are likely to be different. Consider, for example, the visual experience Henry has when he looks at a barn in barn facade country. Due to his environment, this experience is a poor, i.e., unreliable, indicator of the presence of barns. Yet the visual process in play is one that also produces beliefs about chairs, cats, rocks, constellations, and the like. Thus, given that Henry's environment is normal aside from the barn facades, the visual process is reliable, even though the barn percept is not a reliable indicator of barns. Process reliability requires that the inputs in general reliably indicate the outputs in general, but this is far from the kind of reliable indication indicator reliabilism has in mind.

Goldman (2OII) claims that both the process reliability and the fittingness factors are needed to account for evidential justification. The Madeleine/Shirley case shows why fit is not enough, but is there any reason to think that fit is an indispensable element, that process reliability is not enough? Henry's belief that there's a barn in front of him fails to satisfy the fit component, at least as cashed out in indicator reliabilist terms. Nevertheless, he seems to be perfectly well justified, which can be explained by the fact that the more general visual processes he is using are reliable, even in this environment. If we want to understand visual experiences as constituting evidence for perceptual beliefs, their status as evidence seems to be fully captured by the role they play in a reliable process. The other factor---fittingness---is idle.

Reliable indication is neither necessary nor sufficient for process reliability. We have seen why process reliability is an indispensable component in an epistemological theory, but we have not yet seen any distinctive role for indication to play. Process reliability does not entail reliable indication, so an indicator requirement is far from a harmless unpacking of 
what was already included in the process requirement. Indication seems to be neither conducive to justification when it is present without process reliability, nor detrimental to justification when absent, so long as process reliability remains. I think, therefore, that we are better off with a theory of evidence that holds that $e$ is evidence of $b$ for $S$ only if $S$ 's belief that $b$ is the result of a reliable process, among the inputs to which is $e$. This is only a necessary condition, but there is no reason to think that the full and final view will make any reference to reliable indication.

\subsection{Hallucination}

I have been arguing that the reliable indicator component of Goldman's recent theory adds nothing, that he is better off relying on a pure process view. I must confess, however, that there is one sort of case that indicator reliabilism seems to handle better than process reliabilism. To my knowledge, no one has noticed that hallucination poses a problem for process reliabilism, on the grounds that the hallucinatory experience is the result of a different process than veridical experience. Now, I'm no friend of disjunctivism, but even if we individuate processes entirely internally, so that the existence or not of the external object doesn't affect the process type, the hallucinatory and veridical experience

still have different (psychologically different!) etiologies. The veridical experience starts with sense organ stimulation, while the hallucination originates endogenously. Such endogenously originating perceptual processes are highly unreliable, yet the resulting beliefs---the apparently perceptual beliefs that result from convincing hallucinations---are intuitively justified. Indicator reliabilism, of the non-disjunctivist variety, at least, handles this quite nicely on the plausible assumption that hallucination is relatively rare: a given percept, which is common to hallucination and veridical perception, might still reliably indicate the external object.

Hallucination offers a kind of inverse of the barn facade case: process and indicator reliability come apart but this time in different directions. Process reliabilism gets the barn 
case intuitively right; indicator reliabilism gets the hallucination case intuitively right. Given the choice, I would rather get the "wrong" answer on hallucination than on the barn facades. I think that our intuitive attraction to the claim that hallucination yields justification comes not from the assumption that percepts justify what they reliably indicate, but from the assumption that someone who is experientially just like us is justificationally just like us. This is the assumption that drives the notorious New Evil Demon problem for reliabilism. A reliabilist who thinks that de facto or in situ reliability is necessary for justification is going to have to deny that demonworlders are justified, thus claiming that agents could have the very same experiences that accompany our justified beliefs, though these agents are unjustified in these very same beliefs. Maybe there are ways to render this initially counterintuitive claim less counterintuitive. ${ }^{15}$ If so, we might be less convinced that hallucinatory experiences are indeed justification-conferring.

Another consideration against hallucination is that it is sometimes, perhaps always, a species of cognitively penetrated perception, and there is independent reason to think that the cognitive penetration of perception frequently destroys the justification normally enjoyed by perceptual belief. If I seem to hear anger in someone's voice because of some racist prejudice on my part, or I seem to see flirtatious gestures due to wishful thinking, these perceptual beliefs are unjustified. If my fear of spiders causes me to "see" them everywhere I look, my spider beliefs are unjustified. These examples seem to involve unjustified beliefs, even if the resulting experience is identical to a veridical experience of the right sort (Lyons forthcoming a). Hallucinations that result from inadvertent drug ingestion or transient brain damage are not obviously, intuitively, unjustified, but perhaps the consideration of hallucination due to wishful thinking and other blatant forms of cognitive penetration should make us diffident about insisting that hallucination must result in justified belief.

\footnotetext{
${ }^{15}$ As I try to do in Lyons (forthcoming b).
} 
Finally, recall the role reserved for experiences in section I.4 above. In standard cases of convincing hallucination, the agent will have available to her a reliable process which would result in a belief with the same content as the one arrived at via hallucinatory experience. She will have available to her, even in hallucinatory situations, an inferential process (I'm being appeared to F-ly; normally when that happens there's something F nearby; therefore, there's probably something F nearby) that is reliable enough to give her propositional justification for the relevant belief, even if reliabilism implies that it is not justified (i.e., that it is not doxastically justified). Perhaps this can account somewhat for the intuition that seems to favor indicator reliabilism over process reliabilism.

\section{Ex Ante Justification, Propositional Justification, Evidence, and Defeat}

In the last section, I argued that the reliabilist understanding of evidence should involve process reliability, not reliable indication. Here I want to work out the details a bit more, in a way I think Goldman should find agreeable. The heart of reliabilism is a theory of prima facie, ex post/doxastic justification. But it also needs to say something about ultima facie justification (prima facie justification that is not defeated), and it would be nice to say something about propositional and ex ante justification. Evidentialists hold that these concepts are all tightly linked, with evidence serving as the key that unlocks the others. In this section I want to suggest, in a preliminary way, that Goldman can do with processes all of what the evidentialist does with evidence, and more.

Goldman is not very explicit about this, but he seems to equate propositional justification with ex ante justification (e.g., 2008, $\mathrm{xx} \mathrm{II}$; forthcoming $\mathrm{xx}_{4}$ ) and both of these with having evidence in the sense described by the fittingness factor (2OIb, $\mathrm{xx} 26)$. He doesn't say much about defeat in recent works aside from the aforementioned disavowal of ARP. Whatever Goldman's own position, the simplest view about the relation among these four concepts is that ex ante and propositional justification for $p$ are the same and are simply a matter of having evidence for $p$, while defeat is a matter of having rebutting or 
undercutting evidence (i.e., for being ex ante/propositionally justified in either not- $p$ or for a proposition to the effect that one's evidence for $p$ was/is somehow inadequate). Setting defeat temporarily aside and including a generic reliable indicator theory of evidence, we get the following putative equivalences:

$S$ is ex ante justified in believing that $p \equiv S$ is propositionally justified in believing that $p \equiv S$ has evidence that $p \equiv S$ is either in a nondoxastic state that state-indicates $p$ or $S$ is in a (propositionally) justified doxastic state that content-indicates $p$.

\section{I Having Evidence}

I have come close to arguing against the last equivalence here, in arguing that indication is neither necessary nor sufficient for conferring evidence. The baving evidence relation is distinct from, though obviously closely related to, the conferring evidence relation. If a state doesn't confer evidence on $p$, it is not very plausible that being in that state thereby gives someone evidence for $p$.

What should Goldman say instead about what it is to have evidence for something? Recall the suggestion from the end of the last section that when $S$ 's belief that $p$ is based on $e$ by way of process $R, e$ is evidence of $p$ for $S$ only if $R$ is reliable. (There are problems with this understanding of evidence, some of which won't concern us here. $\left.{ }^{16}\right)$ Having evidence should be a matter of being in some mental state that can serve as evidence. Goldman could then say that $S$ has evidence that $p$ at $t$ iff (i) $e$ is a mental state of $S$ 's at $t$, (ii) there's a reliable process in $S$ 's cognitive repertoire at $t$ that maps $e$ to $p$ (i.e., produces $p$ as an output in response to $e$ ), and (iii) any beliefs contained in $e$ are justified.

\footnotetext{
${ }^{16}$ In Lyons 2009, pp. I67-174, I discuss these problems and sketch my preferred (reliabilist) account of the evidential relation. There, unlike here, I stay neutral between indicator and process reliabilist accounts of the "appropriate reliability connection" between the ground and the belief it justifies, focusing instead on the other necessary conditions. Roughly, "basic inferences" are those for which reliability suffices, and "nonbasic inferences" are those for which the agent needs a justified belief in the corresponding conditional, and I claim that the cognitive architecture of the organism determines which inferences are basic for that cognizer and which are not. I won't try to impose all this on Goldman.
} 
There's a lot about this that's imprecise. For one thing, I haven't said whether the justification required by (iii) is doxastic or propositional, ex post or ex ante. ${ }^{17} \mathrm{I}$ also haven't specified whether $e$ is a conscious or even an occurrent state of $S$, and perhaps we want the notion of having evidence to be noncommittal on this score. In the case of stored but nonoccurrent memory beliefs, for example, sometimes we want to say that they count as evidence the agent has (in a loose sense of 'has') and sometimes that they don't (in a stricter sense). Having evidence might even come in degrees, in at least two ways. First, some nonoccurrent states are easier to recall than others; second, two cognitive processes that are both within the cognitive repertoire of the agent (i.e., the agent is capable of executing these processes) might differ significantly in availability. For one thing, it is not always obvious that a given process is relevant or appropriate to use on a given occasion; the processes whose relevance is more obvious seem to be in some intuitive sense more available than the others. Another factor is that some processes are more difficult to execute than others; the more difficult processes should perhaps count as less available, hence less relevant to the agent's evidential status, than the easier processes.

These are the sorts of complications that lead Feldman (I988) to the unusual view he endorses about having evidence. It is understandable that he would be more worried about these than a reliabilist, since the reliabilist has an independent account of prima facie (doxastic) justifiedness, while Feldman explicitly understands doxastic justification in terms of propositional justification. It is better if the vagueness and indeterminacy is associated with the secondary target of analysis, rather than the primary target. It would be good for the reliabilist to clarify the having evidence relation, but (a) some epistemological methodologies require that vagueness in the folk concept by matched by vagueness in the analysis, and it is not implausible that our folk concept of having evidence is vague in just these ways; and (b) doing so doesn't affect the central project of reliabilism: the theory of prima facie, ex post, doxastic justification.

${ }^{17}$ Clearly, however, the formulation should be understood as making a claim about prima facie, rather than ultima facie justification. 
There is one addition that I think needs to be made. As discussed above in section 2.2, many of the cues involved in normal perception fail to count as part of the agent's evidence, because the agent is not even tacitly aware of their evidential significance. The auditory system presumably registers the interaural time difference and interaural level difference, and this results in certain mental states of the agent that feed into reliable processes, but these states don't count as part of the agent's evidence, in any ordinary sense of the term. Thus, I think we need an additional condition for $S$ 's having evidence that $p$ : (iv) $S$ is at least in a position to detect $e$ and appreciate its relevance vis-a-vis the truth of $p$. 'Detect' and 'appreciate' are probably epistemic terms here, and that might be trouble for some theories, but neither Goldman nor I think all epistemic properties can be understood in terms of having evidence, so there are no obvious circularity worries.

\subsection{Propositional and Ex Ante Justification}

Understanding having evidence takes us a ways toward understanding propositional justification. Propositional justification is characterized in different ways by different authors, but the general idea is that it is the kind of justification that attaches to a proposition, whether the subject believes that proposition or not; a propositionally justified proposition (or belief) is one that is somehow the right thing for the subject to believe; it is one for which the subject has justification (or $a$ justification), even if the subject does not justifiedly believe it. Presumably, you can be propositionally justified in believing something that you are unjustified (doxastically) in believing. I'm not aware of a canonical statement of propositional justification, but epistemologists seem to know roughly what's meant. ${ }^{18}$

The term 'ex ante justification' comes from Goldman (1979), and he has two things to say about it. "[I]f $\mathrm{S}$ is trying to decide whether to believe $\mathrm{p}$ and asks our advice, we may tell him that he is 'justified' in believing it. We do not thereby imply that he has a justified belief, since we know he is still suspending judgment. What we mean, roughly, is that he

\footnotetext{
${ }^{18}$ The seminal, even if not currently canonical, statement is from Firth (1978).
} 
would or could be justified if he were to believe p" (p. I24). When he comes to offer a theory of ex ante justification, however, Goldman says that " $S$ is ex ante justified in believing $p$ at $t$ if and only if there is a reliable belief-forming operation available to $S$ which is such that if $S$ applied that operation to his total cognitive state at $t, S$ would believe $p$ at $t$-plus-delta (for a suitably small delta) and that belief would be expost justified" (p. I24). This latter formulation is quite similar to what I offer above concerning having evidence, though without the explicit reference to evidential states.

It is different from the other statement of ex ante justification, quoted above. The first is a counterfactual justifiedness view, while the second is a justification possession view. These can obviously come apart. I can possess a cogent justification for some proposition, even though if I were to believe it, I would believe it for some bad reason. Goldman might have meant for the counterfactual formulation to be a rough and preliminary characterization, to be supplanted by the justification possession formulation, but I think there are two important and distinct concepts here. To keep them straight, I will stipulatively reserve 'ex ante justification' for the counterfactual type of justifiedness (suitably amended, perhaps) and 'propositional justification' for some variety of justification possession.

If evidentialism is true, having evidence can simply be equated with propositional justification (though not with ex ante justification). This, in fact, is a fairly standard statement of evidentialism: $S$ is (propositionally) justified in believing $p$ if, only if, and to the degree that $S$ has evidence for $p$. Having evidence is usually understood in internalist terms by evidentialists, but an evidentialist reliabilist could use something like the view offered above. Despite his recent embrace of evidence, however, Goldman explicitly denies evidentialism: some beliefs are justified even though the agent has no experiential or doxastic evidence for them (2008, 2009a, 20Ira, 20IIb). The above view of having evidence yields a theory of propositional justification simply by discarding the last requirement, making having evidence for $p$ sufficient but not necessary for being propositionally justified 
in believing $p$ (perhaps Goldman never meant to equate the two after all), and leaving us with the following: $S$ is propositionally justified in believing that $p$ at $t$ iff (i) $e$ is a mental state of $S$ 's at $t$, (ii) there's a reliable process in $S$ 's cognitive repertoire at $t$ that maps $e$ to $p$ (i.e., produces $p$ as an output in response to $e$ ), and (iii) any beliefs contained in $e$ are justified. Although it drops a requirement that I think is essential to something's serving as evidence, it shares with evidentialism the view that propositional justification is a matter of the agent's already having within her everything needed for justification.

This last point is well illustrated by a crippling flaw with the simple counterfactual understanding of ex ante justification. I don't currently know how many pages are in the book on my desk, but were I to form a belief about the book's page count, I would do so by turning to the last page and reading the number. This is a reliable enough process, but my readiness to use it in counterfactual situations doesn't make me actually justified---even ex ante---in any belief about the page count, right now, not having looked. If $S$ is ex ante justified now in believing something, this justification must not depend on $S$ 's acquisition, in the counterfactual scenario, of new information, information $S$ does not now possess. The proposed view about propositional justification incorporates this by requiring that $S$ 's mental states and cognitive processes at $t$ be enough to produce doxastic justification, that the process be reliable and able to produce the belief that $p$, given as inputs only those mental states that $S$ is already in. This may be why Goldman (1979) includes the "if $S$ applied that operation to his total cognitive state at $t$ " clause, but without further restrictions on what counts as a belief-forming operation, this fails to guarantee that $S$ receives no new input and thus fails to require that $S$ 's current state is sufficient for justification without that input.

Instead of the simple counterfactual theory, then, we should say that $S$ is ex ante justified in believing that $p$ at $t$ if and only if, if $S$ were to come to believe $p$ using only processes that took as inputs mental states $S$ is in at $t$, then $S$ would be (doxastically) justified in believing $p$. To be ex ante justified, $S$ would have to have a reliable process in her 
cognitive repertoire, and thus ex ante justification implies propositional justification, although propositional justification does not imply ex ante justification.

Nevertheless, there needn't be any overlap between the processes that put $S$ in a position to justifiedly believe $p$ and the processes that $S$ would use in coming to believe $p$, even if we restrict the latter to those that require no new inputs. Suppose you and I share some good evidence for some proposition regarding which we are both currently suspending belief. Suppose further that if we were each to come to believe that proposition, it would be for different reasons: you would believe it because of that evidence, and I would believe it as the result of wishful thinking. You are propositionally and ex ante justified, while I am propositionally justified but not ex ante justified. The ex ante justification seems to make a difference; you are in a better epistemic position than I am, even though we share the same evidence and are equally propositionally justified.

Earlier I argued that having evidence for $p$ was---if having evidence is understood in indicator reliabilist terms---epistemically inert; evidence thus understood does not by itself improve one's epistemic situation. One could have excellent evidence without being even potentially justified. Propositional justification is less epistemically inert than having a reliable indicator, but the contrast between ex ante and propositional justification illustrates how far propositional justification is from the real (doxastic) thing. If one is propositionally justified, then one is in some sense potentially doxastically justified, but it is still a fairly weak sense, for someone could be propositionally justified in believing $p$, even though she would never believe $p$ for any of the good reasons and only ever believe it for the bad reasons. To be ex ante justified is to be close, roughly speaking, to being doxastically justified; to be propositionally justified is not. One can, of course, be propositionally and ex ante justified at the same time, but the positive epistemic status of ex ante justification should not be illicitly attributed to propositional justification as well.

For these reasons, the reliabilist should not give up on the notion of ex ante justification or attempt to subsume it under propositional justification. 
I have tried here to distinguish among three related properties: being ex ante justified, being propositionally justified, and having evidence. I have tried to show that they can be understood in process reliabilist terms, without significant concessions to either indicator reliabilism or to evidentialism. The evidence relation is explicated quite well without an indication component but entirely in terms of process reliability and availability. The slight but significant difference between the proposed accounts of having evidence and of propositional justification highlights the role of justification-conferring processes that do not involve the use of evidence. The distinction between ex ante justification and propositional justification shows that even if one wants to focus on potential, rather than actual justifiedness, there is much of that that has little to do with evidence possession and much to do with psychological propensities.

\subsection{Defeat}

Above, in Section I.3, we saw that Goldman seems to want to do away with the alternative reliable process (ARP) theory of defeat in favor of an evidential account. I made an initial case against such a move, and the recent discussion of propositional justification contributes to this case. Working out the details of ARP would be difficult, to say the least, and I won't try to do it here. But I think that the problem is endemic to the nature of defeat and has little to do with ARP per se.

It is standard to distinguish between evidential and normative defeaters. If you are prima facie justified in believing $p$ but have some reason to believe that not $-p$, or that your original reason for believing $p$ was defective, then you have a rebutting or an undercutting defeater (respectively) (Pollock 1986). Both of these are evidential defeaters, as they consist in one's having evidence for some proposition that threatens the justification of the original belief. To have a normative defeater, on the other hand, is for it to be the case that there is or was something else or something more you should have done in determining whether or not $p$. An evidentialist will have to claim that all normative defeaters are in fact a species of 
evidential defeaters (since ultima facie justification, as well as prima facie justification, is supposed to be entirely a matter of one's evidence), presumably a species of undercutting defeaters. But then it is not the fact that I didn't try to think of obvious counterexamples that defeats the justification for my belief in some generalization; it's the belief that I didn't try to think of counterexamples (or the evidence I have for that belief).

It is not hard to see why an externalist would resist the reduction of normative defeaters to evidential defeaters. It seems that Kornblith's headstrong physicist is unjustified, even if (perhaps partly because) he is too arrogant to hear the objection; and it seems that sloppy reasoning yields unjustified belief, even when we don't think we're reasoning sloppily. But if that's right, if there are irreducibly normative defeaters, then we will need some way to account for them that goes beyond invoking evidential states and relations. ARP offers an obvious way to do this. ${ }^{19}$ Listening to objections and trying to think of counterexamples are reliable and easily available cognitive processes, which, if used in the relevant cases, would have resulted in the agents' not believing as they did.

Even where evidential defeaters are concerned, we need a way of understanding the evidence relation, and as argued above, it is doubtful that we can do this without appealing to the cognitive processes available to the agent. Insofar as defeat is a matter of having evidence, and having evidence is a matter of having certain reliable processes available (i.e., in one's cognitive repertoire), our theory of defeat will have to make use of available reliable processes, which were not used but could have been, as alternatives to the ones that were. So ARP, or something very much like it, will loom large in a reliabilist understanding of defeat even where evidential defeat is concerned. In fact, so called "evidential" defeaters should not be understood in terms of one's having evidence for a proposition that threatens one's justification for $p$, but in terms of one's being propositionally justified in a proposition that threatens one's justification for $p$. Still, ARP or something much like it will be involved.

\footnotetext{
${ }^{19}$ Allowances will have to be made for defeater-defeaters; I'll skip the details here.
} 
There is a way in which the alternative reliable processes originally envisioned by Goldman involve a deeper commitment than the reliable processes invoked in my view of having evidence, propositional justification, and ex ante justification. The latter are all restricted to processes that take as inputs only those states the agent is already in, while there was no such restriction in the original statement of ARP. An adequate theory of defeat will require some restriction on available processes, though probably not the same restriction as the theories of propositional justification and the rest (viz., to processes that take as inputs only those states the agent is already in). To recall a case mentioned earlier, the doctor's belief seems to be ultima facie unjustified if there is new counterevidence in a medical journal that is sitting on her desk and which she has had plenty of time to read. The alternative defeating process here is one that does not merely take as inputs the cognizer's current mental states, and it seems to defeat justification, not just knowledge. On the other hand, if I have excellent reason to think the book on my desk has 256 pages, this belief is not defeated by the fact that if I were to open it and look, I would see that it only has 249. It is far from obvious how one might get both of these cases right at the same time. The easiest, though I think somewhat unsatisfactory, solution is to simply retain the standard restriction on processes, in essence holding that justification for $p$ is defeated whenever the agent is propositionally justified in something that would, if believed, result in her not believing $p$. If a more satisfactory solution is more complicated, this is hardly the fault of ARP; it is a fault of the complicated nature of defeat. If anything, it is a virtue of ARP that it can be permuted in whatever ways are necessary to account for these complexities.

I won't try to figure out the details here. The point I'm hoping to make is simply that Goldman shouldn't abandon ARP in favor of some more evidentialist-friendly theory of defeat. Even evidential defeaters are best understood in terms of available reliable processes, and there are more defeaters than just evidential defeaters.

\section{Conclusion}


Like Goldman, I think process reliabilism needs to incorporate an evidential element. For this and other reasons, the reliabilist should have a view about the scope and nature of evidence. Nevertheless, I think the concessions to evidentialism can be minimized. Rather than allowing that both nonbasic and even some basic beliefs require evidential support, we can hold that only nonbasic beliefs do. While Goldman offers a twofactor view of evidential justification, I proposed a simplified view that dispenses with the objective fittingness factor, construed as reliable indication, in favor of a process-centered account. I then tried to show how Goldman could use this process-centered account as a starting point for treating the sorts of epistemological properties evidentialists have typically focussed on, like evidence possession and propositional justification. The reliabilist can go far beyond the standard evidentialist treatments, however, by extending the processcentered account to ex ante justification and defeat, which don't yield readily to evidentialist treatment.

Again, I am not sure how much of what I have argued here is really incompatible with any of Goldman's serious commitments. Some of the concessions to evidentialism may have been made for the sake of argument, rather than as substantive pieces of new reliabilist doctrine. What I'm doing here is fairly close to defending the old Goldman against the new Goldman. But there is still a great deal of common ground. The new Goldman, the old Goldman, and I all agree that even if reliabilism needs an evidential component, the role of evidence is going to be highly delimited, especially by evidentialist standards, and that the evidential relation will need to be understood in terms of reliability. Even if he resists my simplified views of evidence, defeat, and the like, the central element of these views--process reliability---is obviously something for which Goldman has a high regard. ${ }^{20}$

\section{References:}

\footnotetext{
${ }^{20}$ An earlier version of this paper was presented at the University of Arkansas Epistemology Workshop. Thanks to the audience there, especially Tom Senor and Matt McGrath, for helpful comments.
} 
Alston, W. P. (1988). An internalist externalism. Synthese 74, 265-283.

BonJour, L. (1980). Externalist theories of empirical knowledge. Midwest Studies in Philosophy $5,53^{-7} 73$.

Comesaña, J. (2010). Evidentialist reliabilism. Nous 44, 571--600.

Conee, E. \& R. Feldman (2004). Evidentialism: Essays in epistemology. Oxford: OUP.

----- (2008). Evidence. In Q. Smith, ed., Epistemology: New essays. Oxford: OUP.

---- (201I). Ad Goldman. In T. Dougherty, ed., Evidentialism and its discontents. Oxford: Oxford University Press.

Feldman, R. (1985). Reliability and justification. The Monist 68, 159-174.

----. (1988). Having evidence. In Philosophical analysis. D. F. Austin, ed. 83-104. Kluwer.

----. (2003). Epistemology. Upper Saddle River, NJ: Prentice Hall.

Feldman, R. and E. Conee (1985). Evidentialism. Philosophical Studies 48, 15-34.

Firth, R. (1978). Are epistemic concepts reducible to ethical concepts? In A. Goldman and J. Kim, eds., Values and morals. Dordrecht: Reidel.

Fumerton, R. A. (200I). Classical foundationalism. In M. DePaul, ed., Resurrecting oldfashioned foundationalism. Lanham, MD: Rowman and Littlefield.

Goldman, A. I. (1979). What is justified belief? In George Pappas, ed. Fustification and knowledge. Dordrecht: Reidel.

----. (1992). Epistemic folkways and scientific epistemology. In Liaisons. Cambridge, MA: MIT Press.

----. (2008). Immediate justification and process reliabilism. In Q. Smith, ed., Epistemology: Nerw Essays. Oxford: OUP.

----. (2009a). Internalism, externalism, and the architecture of justification. Fournal of Philosophy 106, 309-33

----. (2009b). Williamson on knowledge and evidence. In D. Pritchard and P. Greenough, eds., Williamson on Knowledge, pp. 73-91. Oxford: Oxford University Press. 
----. (201ra). Commentary on Jack Lyons's Perception and Basic Beliefs. Philosophical Studies 153, $457^{--66 .}$

----. (20Irb). Toward a synthesis of reliabilism and evidentialism? Or: Evidentialism's problems, reliabilism's rescue package. In T. Dougherty, ed., Evidentialism and its discontents. Oxford: Oxford University Press.

----. (forthcoming a). Introduction to OUP collection.

Kelly, T. (2006). Evidence. The Stanford Encyclopedia of Philosophy (Fall 2008 Edition). E. N. Zalta, ed. URL $=<$ http://plato.stanford.edu/archives/fall2oo8/entries/evidence/>.

Kim, J. (I988). What is 'naturalized epistemology'? Philosophical Perspectives 2, 381-405.

Kornblith, H. (1983). Justified belief and epistemically responsible action. The Philosophical Reviere 92 (I), 33-48.

Lehrer, K. (1990). Theory of knowledge. New York: Routledge.

Lyons, J. C. (2009). Perception and basic beliefs: Zombies, modules, and the problem of the external world. New York: Oxford University Press.

----. (forthcoming a). Circularity, reliability, and the cognitive penetrability of perception. Philosophical Issues.

----. (forthcoming b). Should reliabilists be worried about demon worlds? Philosophy and Phenomenological Research.

Pollock, J. (1986). Contemporary theories of knowledge. Savage, MD: Rowman \& Littlefield.

Silins, N. (2005). Deception and evidence. Philosophical Perspectives 19, 375--404.

Williamson, T. (2000). Knowledge and its limits. Oxford: Oxford University Press. 